Ambient Science, 2020: Vol. 07(Sp1); 01-06

DOI:10.21276/ambi.2020.07.sp1.ga01

\title{
Some Common Social Motifs in the Turkish World of Traditional Wrestling
}

\section{Sahin H. Murat*, Duman Savas, Sahin Figen}

Aydýn Adnan MenderesUniversityFaculty of SportSciences, Aydýn/Turkey

Study Area: Aydýn, Turkey

Coordinates: $37^{\circ} 50^{\prime} 32.5824^{\prime \prime}-27^{\circ} 50^{\prime} 56.9724 "$

Key words: Asirtmali Aba Wrestling; Shalwar Wrestling; Karakucak Wrestling; Kusak (Belt) Wrestling; Oil Wrestling

\section{Abstract}

Beyond being a combat sport for Turkish social life, Traditional wrestling expresses social motifs' incarnation over time.These wrestling are also a part of the way societies express themselves and cultural continuity.This study aims to reveal Turkish societies' cultural unity and integrity in different geographies for thousands of years without deteriorating and how important these societies have in their social life. Besides, this study is essential in that traditional wrestling reveals national and spiritual personality. It has been revealed that the cultural and organizational dimensions of some traditional Turkish wrestling, which we have dealt with in this study, show very serious similarities.The response of traditional Turkish wrestling in society and its results is critical in sports and social integrity. Although they emerged in different geographies and different historical processes, traditional wrestling is one of the essential values that reflect the happiness, sorrow, and unity of societies in becoming a nation and creating culture.Here, we see that our traditional wrestling is a sport of struggle and reflects different beautiful social motifs of Turkish society.

Marriage Ceremonies, Boy Child Birth Festivities, Yug Ceremonies, Autumn Festivals Festivals, Peace Wrestling, Boy Naming Festival, Kispet Wearing Ceremonies, New Tent Setting Festival, Ram Festivities, Couple Run Festivities, Harvest Season Festivities, Feast of Sacrifice Festival, Ramadan Festivities, Friday Festivities (This tradition continues in Khorasan. Circumcision ceremonies, military enlistment ceremonies, Liberation Day festivals, Sunday festivals, etc. (Isler, 1997).

Large festivals were held in Turkish tribes in the autumn, with only wrestling in the program. Those died were buried with their weapons, and besides a religious ceremony, wrestling for nine days and nine nights was held around their graves. On the anniversary of his death, thousands of valiant wrestlers would play three days and three nights at their graves again (Keten, 1974). The HiungNu's would organize big wrestling ceremonies to dispel the people's problems. They would continue this wrestling until the beginning of the new month. According to the dead's social situation, these ceremonies are repeated in various competitions such as horse races, wrestling, and pedestrian races on the anniversary of the death. On this 
occasion, great feasts were given (Alpman, 1972).

The sports branches that have existed since the ancient Turks and are still practiced are as follows: wrestling, sword fighting, archery, shooting and horse racing, çögen (çevgan, polo), javelin, spear, kizbörü, gökbörü, cop, oogdaris (wrestling on horseback), tepük, running, hunting, skiing, mountaineering, boxing, bayonet, swimming, kizkovan, beyge, riding, using a mace, bilki, tumdurmaç (water wrestling), sword-shield, sinsin, matrak, tomak, tuluk, weight lifting, throwing, high and long jump, oil mast, rifle shots, slapgame. (Isler, 1997).

Wrestling: It is a combat sport where two people combine their body and intelligence to gain superiority over each other, without a tool (Sahin, 2002). Famous historian Harold Lamb, while talking about the Turks in his work named "Cengiz Han," says "in this country, a man who did not ride a horse or wrestle cannot be allowed to marry a girl (Arig, 1993).

When the historical process of the phenomenon of Traditional Sports is examined, it is seen that the Turkish nation contains physical movement content and expresses some social norms. When we examine wrestling in both social and sportive dimensions, it is seen that the Turks are an indispensable sport of struggle and that it is performed in holidays, weddings, religious ceremonies, national ceremonies, festivals, and even at the graves of the deceased heroes. Wrestling sport, which has been included in every aspect of the Turkish nation's daily life for thousands of years, has also become an essential part of social life. Wrestling symbolizes struggle in Turkish social life; on the other hand, it has transferred some folkloric values in collective integrity to the present day without interruption. It is possible to see these features in almost all traditional Turkish wrestling.

\section{1) Asirtmali Aba Wrestling:}

The asirtmali aba wrestling expresses itself as the reflection of people's spiritual and physical needs as a whole, both in the past and today. Aba wrestling also appears as a cultural accumulation of Turkish people's daily life and values in social dimensions. In another approach, Turks' practice of wrestling during the periods they lived in Central Asia originated from the need to combine their spiritual feelings and thoughts with the body, depending on those days' living standards and culture. In terms of reflecting the Turkish nation's material and spiritual personality, the asirtmali aba wrestling is an ancestor sport, but it is one of the traditions that reveal the Turkish nation's sports culture. As traditional wrestling of the Turks with its historical past, dress, rules, and

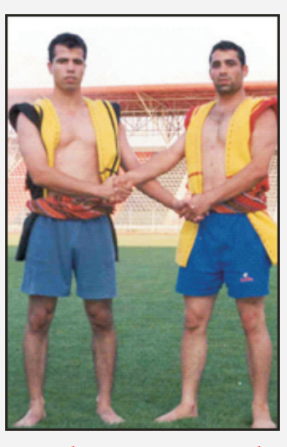

Plate-1:Asirtmali Aba Wrestling techniques, asirtmali aba wrestling has survived and preserved. Asirtmali aba wrestling, one of Turkish culture's traditional wrestling, is practiced in Turkey's Gaziantep region (Sahin, 2003).

1.1) Weddings, Festivals, and Ceremonies in Asirtmali Aba Wrestling:

One of the traditions that are as important as both history, culture, and theatrical village games is Asirtmali Aba Wrestling. This traditional wrestling has survived intact for centuries. Asirtmali aba wrestling is usually held at the end of the harvest and weddings. The wedding owner slaughtered a sacrifice before the wedding and invited his peasant and relatives to dinner. After the meal, he announced how many villages he will send readings (okuntu in Turkish) (calling cards that invite local villages to weddings and wrestling). Often wealthy families send readings to other villages at their wedding. The wedding owner calculates how many people can come to this wedding and informs the villagers and their relatives. The village people decide how many people they can host among themselves, without involving the wedding owner (Sahin, 1995b).

The reader (male or female) who transmits the reading to the villages wanders the villages where they are expected to go and convey it. In these weddings, the reader can sometimes be a woman. This female reader, a bag on her shoulder, walks around all who will be invited. The girl or the boy conveys his/her mother's greetings to the wife of the house he/she went to. In other words, he/she invites the female part of the places he/she goes to the wedding. This reader sometimes gives a sprig of flowers or mother-ofpearl where he/she goes. The reader is given money, must (grape molasses), or cereal product (lentil, wheat, etc.) for telling the good news (Yener, 1947). At the end of the reading, it becomes more or less clear on how many people will come to the wedding. The wedding owner starts preparations for the wedding in the village after the number of guests is determined. The villagers complete all their homes to welcome the guests and start to wait for them. The guests start to come to the village where the wedding will take place one week before the wedding takes place. If the weather is fine, guests are welcome on the village's threshing floor. Cushions are laid here; mattresses are opened. The people living in that region almost compete with each other to continue this tradition. Because of any negativity to be experienced, there is a great shame and embarrassment for the village's people. Generally, village leaders make great efforts to prevent these dire situations. On the other hand, young people pursue and serve guests and young girls until the end of the wedding (Keskin, 1978). There are not many people from the villages where readings are sent to neither weddings nor wrestling. There may be reasons such as resentment and quarrels under not inviting to the wedding. Events like these reduce the quality of 
wrestling at weddings. Villages with good wrestlers may not want to participate in these wrestling because of resentment. When reading begins to be sent to other villages, shawm-and-drum starts to be played in the village where the wedding will take place. The guests who receive the reading go to the village where the wedding will be held with their village's wrestlers. They stop 500-60o meters from the entrance to the village. They inform their arrival by throwing a gun in the air. Hearing the gunf ire, wedding owners and villagers rush to greet the guests. The guests are greeted with a shawm-and-drum and are taken to the threshing floor, accompanied by a shawm-and-drum. They rest on cushions and mattresses prepared for them. During the rest period, guests are served cold water, buttermilk, and bitter coffee. All the people of the village line up at the threshing floor to welcome the guests. After every one, old and young, says welcome to the guests, deep conversations begin on the threshing floor and those who have not seen each other for a long time. After resting for a while, the guests are taken to the houses; the villagers will host them for dinner.

Meanwhile, the shawm-and-drum plays the "Cezayir" song. After the meals are eaten, the shawm-and-drum gathers the guests and brings them to the wedding venue. During the wedding, animals are sacrificed in the village. Meanwhile, the village women serve all the dishes of the Gaziantep table in the best way possible. This event becomes a source of honor and pride for the wedding owner. As the wrestling day approaches, preparations are accelerated in the village. Thresher is extracted from stones and thorns. The ground where the wrestling will take place is softened and made suitable. The wrestlers who will participate in the wrestling start their preparations slowly.

Meanwhile, the guests surround the area where the wrestling will take place. After all the preparations are fulfilled, wrestling starts. Wrestling always takes place between "Dere" villagers and "Pekmezci" villages. Incoming guests gather in whichever village wrestler is. Wrestling often does not end in one day; it lasts for a few days (Keskin, 1978).

While some wrestlers come to the village with a shawmand-drum, some enter the village at night to not know and hear that they are coming. He spends the night at an acquaintance's house. He aims to confront his opponent at an unexpected moment and surprise him and take advantage of this situation. When this wrestler suddenly appears out of nowhere, a buzz breaks out at the threshing floor. This time, the other party may think that their wrestlers can be beaten. The peasants of the wrestler who later got into the pit are very pleased with this job. The neutral audience is delightful as they will watch enjoyable wrestling.

Meanwhile, as wrestling is getting even more glorious, the wedding owner's joy can be read in their eyes. Worried that their wrestlers will be defeated, other villagers send horse riders to the villages to bring a better wrestler against this wrestler. Because they do not intend to lose the ball (prize), the sent horse rider found the wrestler in their village, tell the importance of the situation. He says it is a matter of honor, that he should come and wrestle no matter what, convince him of this situation. Accepting this, the wrestler and the horse take the road to the village where the wedding will take place. It would be very different to welcome a wrestler who comes to such wrestling later. The welcome is much more sincere and warm. Many of those who watch the wrestling run to the incoming wrestler. He is almost a hero in the eyes of his villagers. The villagers take this wrestler off the horse and bring it towards the pit (wrestling area), to the private square. If the wrestler is tired, he will rest for a while. If he is not tired, he is undressed and brought to the pit. Only men can watch the wrestling by lining up around the threshing floor, and women go to the roofs of the houses to watch the wrestling. Women are forbidden to watch the wrestling close, and it is a shame, as wrestling takes place with short pants or without it. When the wrestlers start to wrestle in the pit, the audience's excitement is also at its peak (Gökdemir, 1978).

When the match is over, the winner wins the ball (prize). There is no Pesrev in Aba wrestling. Also, the defeated wrestler kisses the hand of the victorious wrestler. He kisses the forehead of the defeated wrestler. The defeated wrestler takes the victorious wrestler on his shoulder or back and carries them out of the wrestling area. Besides, because he is victorious, he glorif ies his village's honor and dignity and audience. The villager of the victorious wrestler is also very pleased with this job. The defeated party leaves the wrestling field in deep sorrow. Such wrestling will be remembered for years. All the villagers return to their daily life and work until a new reading arrives.

Cheers are not allowed in Aba wrestling: the aim is not to cause any incidents. If the wrestlers cheer verbally or actively during or as a result of wrestling, this event overshadows the aba wrestling. Big fights had broken out among the wrestler's spectators who were defeated or defeated due to the cheers. As a result of these fights, the events lead to bloodshed and death.

For this reason, it is a rule not to cheer in Aba wrestling. Those who cheer are condemned by those who watch wrestling and are not respected in that society during wrestling. However, as people know this, they stay away from cheering for wrestlers during wrestling. Besides, this behavior that has been going on for many years has become a radical expression of the moral rules of that society. Those who watched wrestling for a long time never fall into the mistake of cheering. They even warn the young people next to them or those who do not know this rule. Wrestlers never expect cheers from the audience. Because for them, it is the most precious and most robust applause for them to fill 
their hearts, be applauded in their hearts, and win the love of the audience. This is the most prominent feature that distinguishes Aba wrestling from other sports.

\section{2) Shalwar Wrestling:}

Shalwar wrestling is held in Kahramanmaras district and villages in our country. Shalwar wrestling is a type of wrestling performed by the Turkmen in ancient times. In the past, wrestling with shalwars in long pirpit and kispet is now performed with short shalwar upon the customs' gradual disappearance. All games are performed standing in shalwar wrestling. The wrestler who defeated his opponent would not take off the shalwar without wrestling with at least two supporters of the defeated wrestler (Güven, 1992). As in Aba Wrestling, village wrestling was also held in Shalwar Wrestling. Especially at village weddings, the wedding owner and the village's notables sent a roll of cloth called okuntu (reading) and invited the wrestlers to weddings in the village. The wrestler who received the reading knew that this meant an invitation to the wrestling at the wedding.

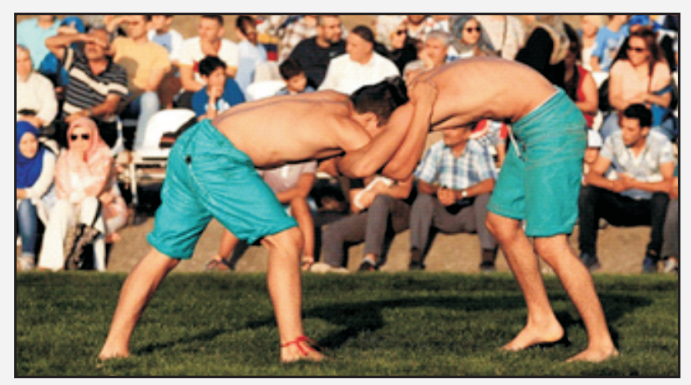

Plate-2: Shalwar Wrestling

It could be a ball of cloth or a shirt, undershirt, or towel. The wrestlers who took reading and their supporters would go to the village where the wrestling would take place that week. Each village made its team. For example, ten people would be on one side; ten people would be on the other side; whichever village won, that village would receive the bonus. The bonus could sometimes be a ram, cattle, or goat. The village, which won the bonus, would sacrifice animals in their village and host a feast for all the villagers. Thus, the joy and interdependence of the peasants would have increased.

A wrestler would wrestle with 3-4 wrestlers before leaving the square. In our wrestling, there would be shawmand-drum. Warfare songs would play (Köroglu). When the wrestler knocked over his opponent, the drums would be cut off suddenly. The people also respected wrestlers with degrees. The old wrestlers would be the referee, had no unique clothes, but daily clothes, either a stick or just used their hands. They would stop or start wrestling by touching the wrestlers. The old wrestlers advise the wrestlers of the village. In wrestling, the drummers' wages were paid by the supporters and fans of the wrestler while wearing the winning wrestler's top. The wrestler was honored on this occasion (Bay, 2019). In an interview with a former wrestler from the village of Igde, who is elderly and illiterate from
Elbistan, about salwar wrestling in 1999, it was said, "Why don't you make a move to your opponent that you dropped in salwar wrestling? "You put the man down and put him in an incapacitated situation; you cannot go on such a man in Turkish tradition" (Dogan, 2010).

\section{3) Karakucak Wrestling:}

In Karakucak wrestling, one of theindispensable ceremonies of our weddings and holidays, the drum and zurna are played throughout the wrestling. In Karakucak wrestling, the wrestlers wear "pirpit" made of goat hair or tent cloth and usually in black color. In Karakucak wrestling, the wrestlers are divided into their rankings according to their age, strength, strength, and skill. Other rankings are almost the same with oil wrestling, although it varies according to the regions. Karakucak won in wrestling; is that the navel sees stars. Since Karakucak is not as slow as oil wrestling, it tires wrestlers in a short time (Akkurt, 2008).

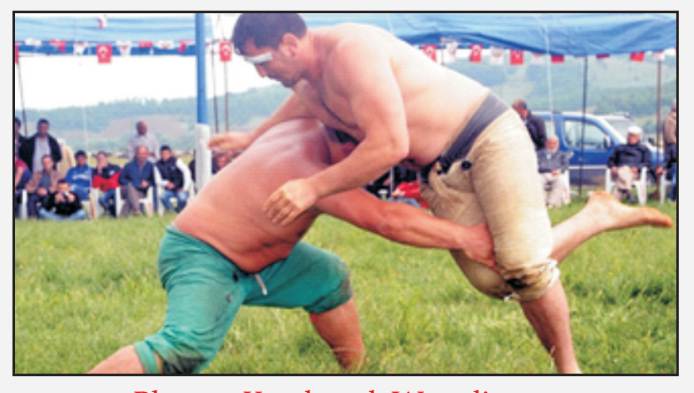

4) Kusak (Belt) Whẩ Karestling: Kusak wrestling, which is called "Küres" in the Crimean dialect, is performed in special entertainments called "Hidirellez" and "Tepres" as the traditions of the Crimean Turks. This wrestling has its characteristics. Wrestlers do not get undressed in this wrestling; they only take off their jackets and shoes. This wrestling, held in Uzbekistan and other countries where Uzbeks are located, has carried

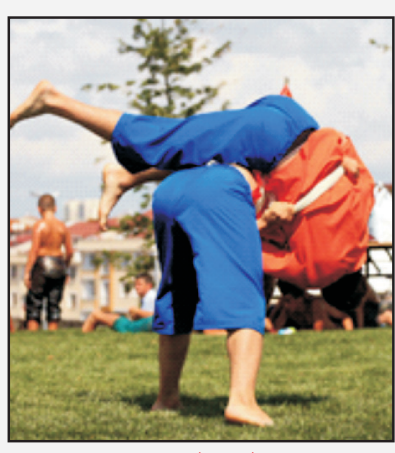

Plate-4: Kusak (Belt) Wrestling existence from past to the present. This wrestling is performed at weddings and holidays. Children gather in the square. The oldest of them become the "Anabasi." All other children except the "Anabasi" sit in a large circle. The "parent" also takes the hand of that child. He announces that they will hold wrestling by saying the names of the two children.

A waist tie (sash) is wrapped around the waist of the children. Children try to tear each other down by wrapping the ends of those ties in their hands. Whichever one lifts the other and lays it down wins the wrestling. The wrestler lifts his opponent on his lap, cuts his foot off the ground, takes 
him around, and asks the children. "Onge or Çopke?" If the children say "Onge," he leaves the opponent without lying on the floor, and if they say "Çopke," he lays the opponent down. The parent asks the children, "has it finished?" The children shout, "Finish." The anabasi holding the victorious child's hand and asks the children, "Is there any rival to this wrestler?" If no one appears after threequestions, that boy is chosen as the best wrestler. A gift is given to the child. If there is another wrestler, he will also wrestle with him (Özhan, Muradoglu, 1997).

\section{5) Oil Wrestling:}

Today, the generally accepted belief regarding the

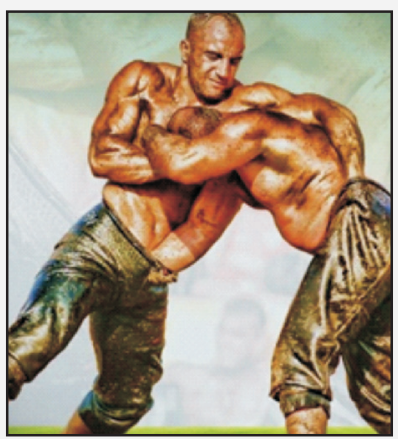

Plate-5: Oil Wrestling beginning date of Kirkpinar wrestling is that Kirkpinar started with the conquest of Edirne in 1361. However, there are also efforts to retract and rebuild Kirkpinar's history. Of course, Osmanogullari, who are members of the Kayi tribe, carried these traditions from Turkistan geography to Anatolia. The Ottoman Turks invited people to share their happy times by putting the wax in the "nahl" as an invitation, making flower and tree motifs from it, embroidering the leaves with silver into a "The Tree of Blessing," and painting one side of the wax in red. In this way, the meaning of the ritual of sending red-bottomed candles to the guests in Kirkpinar Oil Wrestling (1361), which has been organized since the foundation of the Ottoman Empire; "We have a wedding, a festival! We are waiting for you all to this light and enlightenment with great desire" (Karadogan, 2020). At the wedding wrestling, the enamel, circumference, towel, woolen socks, and similar items were given from the bride's dowry. Dobrice and the Crimean Turks used to call these awards suitable for daily use "Akse" and design them in nine pieces. At the end of the competitions, the wrestlers' awards as fabric were colored, printed, silk, or cotton fabric, probably six cubits (4-5 meters) long (Ayag, 1983).

The red-bottomed candle has particular importance for Kirkpinar Oil Wrestling. Twenty or twenty-five days before the start of Hidirellez, red-bottomed candles are sent to all the neighboring provinces and state officials by KirkpinarAgasi. The candles were hung on the ceiling of the café, which is the most popular place in the province, the district where they were sent and where the people, generally the male population, were most popular, and the people were invited to Edirne to wrestling competitions. Ten or fifteen days before Hidirellez, Simonia Village residents used to build the Kirkpinar neighborhood and the surrounding area, seating areas for guests to receive the invitation, barracks for their accommodation, and makeshift shops for shopping. The agha welcomed his guests started in the place called "Selim's Tomb" when the city watcher waved a flag to the other watcher waiting at the gate of Kirkpinar district. When the bands reached the door, the shawm-and-drum would bring the foal on a red cloth to the guests, a sign of care (Karadogan, 2020).

\section{Conclusion:}

Traditional Turkish wrestling, which has existed from past to present undervarious names, is a physical movement and a cultural reflection of the societies in which it lives. Symbols, rituals, and ceremonies that bring societies together use social and cultural tools while ensuring the strengthening and consolidation of ties. Sport is one of the most prominent of these tools. Sports is the most potent connector that brings together traditions and societies and enables beliefs and value judgments to continue and refresh (Karadogan, 2020).

With this study, it has been revealed that the societies living in Anatolia and Central Asia keep their traditions alive without any change or deformation. The cultural integrity that emerges here reveals social life's existence in meaning and integrity in Turkish societies. Even if they have different geographies and different historical backgrounds, these cultural values and heritages have survived until today without losing their meaning.

Wrestling is one of the values that best reflects the Turkish community life among cultural heritage. Wrestling is one of the primary values that can reflect the Turkish society's social values, national and spiritual personalities in daily life. Weddings, festivals, entertainment, funeral ceremonies integrated with wrestling had the opportunity to express Turkish society's beauties, joy, and sorrow. When we look at the spiritual personality dimension of traditional Turkish wrestling, it is seen that national and moral values are kept alive, courage, bravery, and bravery are at the forefront, discipline, obedience to rules, and social integrity have been a part of weddings and funeral ceremonies throughout history. It is vital to bring people together, keep them together, reflect the customs and traditions in integrity, protect and feed the poor, the strong do not oppress the weak, solidarity, and hosting guests is essential. The most crucial difference to be underlined here is that the audience cannot applaud the winner in aba wrestling. The wrestler who is victorious in the aba wrestling cannot be applauded because the defeated wrestler is not offended anymore. Perhaps the only sport in the world where the winner or the team is not applauded is aba wrestling. This is the result of a virtuous understanding of not allowing a defeated person to be further oppressed. This virtuous and graceful behavior is the most critical feature that distinguishes aba wrestling from other sports branches in the world. When we examine the organizational dimension of traditional Turkish wrestling, it was determined that the wrestlers invited to wrestling were invited to wrestling in 
the same way, readings were sent as an invitation tool, drums and zurna were used in all wrestling, and the wrestling areas were threshing places in the villages. It is seen that the referees who manage the wrestling are elderly wrestlers, wrestling continues to be held before, during, and after the wedding, the wrestling is given a coach, cattle or goat as a prize, and all wrestling is performed with traditional clothes.

\section{References:}

Akkurt, M. (2008): Historical Development of Traditional Wrestling Made in Kahramanmaraș and Perceptions by the Society, Kahramanmaraş Sütçü İmam University Social Sciences Institute Physical Education and Sports Department, Master Thesis, Kahramanmaraş.

Alpman, C. (1972): Physical Education and Development Throughout the Ages, General Directorate of Youth and Sports Publications:1, s. 15-35, İstanbul Turkey.

Ary̆ğ, N. (1993): Asil Spor Wrestling, Prime Ministry G.S.G.M., Publication No: 118, s. 1-29, Ankara, Turkey.

Ayağ, Ali (1983): Turkish Sports Tradition and Kırkpınar Wrestling, Divan Pub., İstanbul, Turkey.

Bay, E. (2019): Practices of Traditional Turkish Sports Short Baggy Wrestling and Examination of Cultural Dimension, Aydin Adnan Menderes University Institute of Health Sciences Physical Education and Sports Education Master's Thesis, Aydın, Turkey.

Doğan, V. (2010): Kahramanmaraş Şalvar Wrestling and Comparison with Similarities in the World, Ondokuz Mayıs University Institute of Health Sciences, Department of Physical Education and Sports, Master's Thesis, Samsun, Turkey.

Gökdemir, K. (1978): Karakucak and Aba Wrestling, Unpublished Undergraduate Thesis, 19 Mayis Youth and Sports Academy, s. 22-29, Ankara, Turkey.
Güven, Ö. (1992): Sport Culture in Turks”, Atatürk High Institution of Culture, Language and History, Atatürk Cultural Center Publications, Issue: 57, Series of Images from Turkish Culture, Issue:16, s. 4-16, Ankara, Turkey.

İșler, H. (1997): Examination of Traditional Aba and Shalwar Wrestling in Terms of Historical Origins, Spread Areas, Organization Types and Functions, Unpublished Doctorate Thesis, Gazi University, Institute of Health Sciences, Department of Physical Education and Sports, s. 4-189, Ankara, Turkey.

Karadoğan, U.C. (2020): Cultural Heritage Extending From Past to Future: Kirkpınar Oil Wrestling, Ankara University Turkish Revolution History Institute, PhD Thesis, Ankara, Turkey.

Keskin, E. (1978): Our Aba wrestling, s.16-68, Ankara, Turkey.

Keten, M. (1974): Sports in Turkey, s.25-26, Ankara, Turkey.

Özhan, M., Muradoğlu, M. (1997): Muradoğlu, M. Children's Games in Turkish Republics, Ministry of Culture Publications, s.90-91, Ankara, Turkey.

Şahin, H.M. (1995a): Culture and Sports, Gaziantep Spor 27 Newspaper, s.3, 17.05.1995a.

Şahin, H.M. (1995b): Overclocked Aba Wrestling, Unpublished Undergraduate Thesis, Gazi University School of Physical Education and Sports, s.1-6o, Ankara, Turkey.

Şahin, H.M. (2002): Dictionary of Basic Concepts in Physical Education and Sports, Gaziantepspor Club Sports Education Publications, Publication No: 1, Nobel Yayın Dağıtım, 1st Edition, Ankara, Turkey.

Şahin, H.M. (2003): Aba Wrestling in Turkish Sports Culture, Gaziantepspor Club Sports Education Publications, Publication No: 4, Nobel Publication Distribution, Enhanced 2nd Edition, Ankara, Turkey.

Yener, Ş.S. (1947): Getting Married in Gaziantep, Folklore Compilations, Bașpınar Gaziantep Community Center Journal, Volume: 4, Issue:87-2, s.10, Gaziantep, Turkey 